\title{
EL POPULISMO PENAL EN COLOMBIA: PROPUESTA PARA UN DEBATE INCONGLUSO*
}

\author{
CRIMINAL POPULISM IN COLOMBIA: \\ PROPOSAL FOR AN UNFINISHED DISCUSSION
}

\section{Juan Pablo SARMiento E.** \\ Enith Carolina BULA*** \\ Carolina MARIÑO M.****}

RESUMEN: El presente documento argumenta que el populismo penal ha sido interpretado y caracterizado de diversas maneras, pero que, en realidad, no se han planteado propuestas para establecer un "umbral" que permita definir cuándo se trata de una reforma penal legítima y necesaria, y cuándo estamos ante una populista o reaccionaria. Este trabajo propone un modelo aplicado a reformas penales que se podrían considerar populistas, y así, ofrecer un test que permita dar un paso hacia la teoría del populismo penal.

Palabras clave: populismo penal, fetichismo legal, eficacia simbólica del derecho, derecho penal de excepción.
ABSTRACT: This paper argues that criminal populism has been interpreted and characterized in many ways, but no proposals have been made to establish $a$ "threshold" to define when a criminal reform is legitimate and necessary, or when it is populist or reactionary. This paper proposes a model applied to penal reforms that could be considered populist, and thus, offer a test that allows to take a step towards the theory of criminal populism.

Keywords: Criminal populism, legal fetishism, symbolic efficacy of law, criminal law of exception

* Artículo recibido el 20 de abril de 2017 y aceptado para su publicación el 11 de mayo de 2019.

** ORCID: 0000-0002-7303-3300. Abogado por la Pontificia Universidad Javeriana, magíster y doctorado en derecho de la Universidad de los Andes. Profesor de la Universidad del Norte. Director del Grupo de Litigio de Interés Público de la Universidad del Norte. Correo electrónico:jpsarmiento@uninorte.edu.co,jua-sarm@uniandes.edu.co.

*** ORCID: 0000-0002-5545-4013. Abogada y politóloga de la Universidad del Norte, especialista en derecho penal de la misma institución; estudiante de maestría en derecho de la Universidad de los Andes. Correo electrónico: enithb@uninorte.edu.co.

**** ORCID: 0000-0002-5704-8465. Ingeniera industrial por el Politécnico Grancolombiano, magíster en ingeniería industrial de la Universidad del Norte, y estudiante de doctorado en Estadística e Investigación de Operaciones en la Universidad de Valencia España. Correo electrónico:inmaman@alumni.uv.es

Boletín Mexicano de Derecho Comparado, nueva serie, año LI, núm. 155, mayo-agosto de 2019, pp. 1047-1079. 
SUMARIO: I. Introducción. II. Populismo penal, derecho penal de excepción y enemigos isomórficos: un debate inconcluso. III. Una propuesta para releer el populismo punitivo. IV. Conclusiones. V. Referencias bibliográficas.

\section{INTRODUCGIÓN}

¿Cómo debería reaccionar el legislador a actos de atrocidad y a la cotidianidad de conductas que cuestionan cualquier dimensión de la convivencia humana? ¿Cuáles son los límites que debería considerar el legislador al momento de crear una nueva conducta penal? En varias oportunidades, ante crímenes atroces o actos contra el patrimonio que se cometen a gran escala, el legislador ha reaccionado creando nuevos delitos o incrementando la punición de los que ya existen, acudiendo a la ficción del poder fáctico de lo normativo y la prevención general y especial de sanciones privativas de la libertad contra conductas que se pueden considerar objetivamente contrarias a la dignidad humana o al patrimonio.

Sin embargo, las frecuentes alteraciones al sistema penal muchas veces conducen a un desquiciado frenesí, que es calificado por muchos como "populismo penal", "autoritarismo" penal o "fetichismo legal". Con todo, existe una innegable necesidad de ajustar el sistema jurídico a paradigmas provisionales y transitorios y a direccionar conductas individuales que amenazan la dignidad humana y otros bienes jurídicos. Luego, emergen importantes cuestionamientos, no sólo a un derecho penal que falla sistemática y estructuralmente, sino a la legitimidad de la decisión del legislador de expandir todavía más, un estatuto de conductas típicas, a pesar de contar con un aparato estatal famélico, que no tiene capacidad de desplegar un proceso penal en términos razonables, ni cuenta con espacios de reclusión suficientes. Junto a esta expansión irracional del derecho penal, se han incluido beneficios procesales, que podrían ser observados como parte de la justicia "premial" o de "apremio" (Restrepo 2015, 232), que raras veces podría beneficiar a la población carcelaria más vulnerable.

Lo antedicho nos conduce a una innegable necesidad de definir o, cuando menos, insinuar un "umbral", entendiendo que no cualquier reforma penal es populismo, y donde no todas las reformas legales son adversas al sistema penal. Es notable que uno de los factores que parecería permear la genealogía de las reformas penales recientes y capturar rápidamente los debates públicos y políticos es la manera en que las ma- 
yorías reaccionan, desde cualquiera de las orillas ideológicas dominantes, demandando más seguridad, protección al patrimonio privado y a los mercados financieros y la transparencia de negocios con el Estado, o la protección a la familia, el medio ambiente, las mujeres, los niños o minorías raciales, etcétera. En cualquier escenario, como se presentará con posterioridad, el derecho penal se convierte en el protagonista en una arena donde se le reconoce como el portador de todos los males, y a la vez, de todas las soluciones, con mayor razón, cuando ocurren actos atroces o cuando la cotidianidad y frecuencia de delitos y reincidencias producen la certeza de un Estado que carece de elementos suficientes para garantizar la eficacia del aparato represivo.

Es allí donde el populismo punitivo, se expondrá más adelante, es reconocido como un dispositivo utilizado con fines electorales, o como una apelación al "pueblo", quien definiría los problemas que le conciernen y cómo debe afrontarlos. Con todo, lo que ha resultado es un empobrecimiento significativo del sistema y del debate del derecho penal, una competencia por parecer más "duros contra el crimen" y una muy útil emergencia crónica, que convierten a estatutos que limitan libertades públicas y extienden el derecho penal en legislación permanente y normalizada (González 2015, 67-70).

Existe, además, un efecto bastante nocivo para la eficacia del sistema penal derivado del populismo punitivo. Se trata de la "inflación normativa" (Sarmiento 2013), que conduce a que, dada la expansión del sistema penal, las autoridades encargadas de la investigación y juzgamiento tengan que afrontar un nuevo estatuto y conjunto de delitos, pero cuenten con los mismos recursos para perseguir las nuevas y viejas conductas. Esta situación es prevista por el mismo destinatario de la norma, quien encuentra que la punición de un delito nuevo cuenta con pocas probabilidades de un juzgamiento efectivo, y con ello, la disuasión que se espera del derecho penal se erosiona rápidamente (Kleiman 2015). Inclusive, el modelo propuesto por el profesor Kleiman probaría que la pérdida de capacidad disuasiva del delito no sólo afectaría al nuevo estatuto, sino a las conductas que eran previstas por normas previas a la reforma, y con ello, podría conducir al derrumbamiento de la capacidad preventiva de la pena.

Para ofrecer entonces una visión más completa y robusta de qué se ha entendido por populismo penal, sus huellas y prácticas más frecuentes, se iniciará la presentación de un breve estado del arte y aportes que ofrecen 
un marco operacional para descifrar el populismo punitivo (I), para luego, arribar a una propuesta para construir "umbral" sobre el populismo y evaluar la reforma legislativa a la luz de los anteriores aportes (II).

\section{POPULISMO PENAL, DERECHO PENAL DE EXCEPCIÓN Y ENEMIGOS ISOMÓRFICOS: UN DEBATE INCONCLUSO}

El derecho penal se ciñe a unos fines declarados como la retribución, la prevención general y especial positiva y negativa y la protección al condenado. Con todo, el derecho penal ha sido incapaz de cumplir con tales finalidades, y, además, ha desarrollado funciones no declaradas, que han sido una muestra evidente de la instrumentalización política del derecho penal. De esa forma, el derecho penal realiza funciones que han implicado una expansión punitiva exacerbada e irracional, como el populismo punitivo, la criminalización de la pobreza, la eliminación del "enemigo", entre otras.

El populismo punitivo ha sido un tema abordado por distintos autores para intentar explicar la irracionalidad que ha experimentado la política criminal y las tendencias expansionistas del derecho penal en diversos contextos. En Colombia, por ejemplo, tal como lo han reconocido la Comisión Asesora de Política Criminal (2012: 34) y la Corte Constitucional (Sentencia T-762 de 2015), la política criminal ha estado marcada por una tendencia al populismo punitivo.

De acuerdo con Larrauri (2006, 15, citando a Bottoms 1995), el populismo punitivo se refiere al uso del derecho penal por parte de los gobernantes con base en tres presupuestos básicos:

a) Las penas más elevadas pueden disminuir el delito.

b) Las penas ayudan a reforzar el consenso moral social.

c) El uso del derecho penal permite obtener beneficios electorales.

Los dos primeros presupuestos señalados se relacionan directamente con el planteamiento de las teorías de la prevención general negativa y positiva, respectivamente. Aunque tales teorías han sido ampliamente criticadas, constituyen dos fines declarados de la pena que son reconocidos desde el mismo Código Penal en sus principios rectores (artículo 4o.). El 
tercer presupuesto permite destacar la manera en que los políticos tratan de explotar el consenso de la ciudadanía por medio de la oferta electoral de seguridad y de erradicación del delito, sin atender a los distintos problemas de carácter social que se han generado a partir de la adopción de modelo económico neoliberal. El debate electoral se centra entonces en explotar el miedo que la población siente frente al delito, proponiendo como solución efectiva la expansión normativa del delito, que implica, entre otros aspectos, el establecimiento de penas elevadas, el cambio del ideal resocializador por la inocuización mediante penas degradantes, la garantía de los derechos de las víctimas, como contrapuestos a los derechos de los "delincuentes", la privatización de la función de control del delito, entre otros aspectos (Martínez 2008, 184). En ese sentido, el populismo punitivo implica tanto la instrumentalización política, particularmente electoral, de la cuestión penal, como la activa participación de la ciudadanía en la configuración de la política criminal del Estado (Muñoz 2009, 34).

Asimismo, Ferrajoli $(2013$, 60) considera que el populismo punitivo comprende las estrategias enmarcadas en el área de la seguridad que se orientan a lograr el consenso popular mediante la demagogia, en respuesta al miedo que genera la criminalidad haciendo "un uso coyuntural del derecho penal, tan duramente represivo y antigarantista, como ineficaz, respecto a las declaradas finalidades de prevención". En ese sentido, Bassombrío y Dammert (2013, 6-7) atribuyen tres características al populismo punitivo: demasiada preocupación de los políticos por los sentimientos del electorado, para establecer un vínculo con la opinión pública; el énfasis de los políticos en presunciones improbadas y simplistas acerca de la criminalidad y la violencia, y la falta de importancia que los políticos dan a los efectos causados por las medidas penales que utilizan.

Además de reconocer la búsqueda del consenso ciudadano a través de la demagogia, Ferrajoli aporta otros elementos a tener en cuenta para efectos de comprender el populismo punitivo. Particularmente, el autor italiano destaca la ineficacia propia de las medidas del derecho penal expansivo, de cara a la prevención de los delitos a los que tanto teme la población. Este hecho, propio del populismo punitivo, está relacionado con la politización de los procesos de decisión legislativa y política, que Garland (2005) explica y que González reitera (2015), en donde es el "sentir 
popular" quien impone los márgenes, y extiende y contrae las conductas objeto de sanción.

De ese modo, en los casos de populismo punitivo, la élite política desatiende la voz de los expertos, quienes pueden analizar la verdadera eficacia de las medidas punitivas represivas y su conformidad con los principios limitadores del derecho penal, para atender a la voz de la opinión pública desinformada, de la sociedad atemorizada y de las víctimas que buscan justicia retaliativa. ${ }^{1} \mathrm{Al}$ actuar de ese modo, los gobernantes y congresistas sacan provecho de lo que, de acuerdo con García (2014, 48), puede denominarse como la función de apaciguamiento del derecho, la cual permite resolver situaciones problemáticas a través de la eficacia simbólica del mismo.

Siguiendo a García (2014), la eficacia simbólica del derecho logra sus fines mediante la difusión de una idea de justicia, de autoridad o de legitimidad (2014:99), puesto que "su fuerza radica en el impacto mental que produce un discurso legal con capacidad para establecer la diferencia entre lo lícito y lo ilícito, lo justo y lo injusto, lo verdadero y lo falso y entendido como parte fundamental de instituciones político-jurídicas legítimas" (2014, 92).

Ahora bien, Uribe (2012) propone un concepto distinto, conforme al cual el populismo punitivo se da en las sociedades en las cuales: 1) se utilice un derecho penal autoritario, 2) sectores políticos dominantes utilicen el derecho penal para efectos electorales sin importar las consecuencias de efectividad o de daño social de la norma; 3) que exista una particular sensibilidad social producida por la emergencia social inherente al modelo político neoconservador y económico neoliberal propio de la globalización, los problemas de la modernidad y de la gran ciudad; los principales medidores de esta sensación son la desigualdad económica y la inestabilidad laboral; 4) la sociedad debe presentar una escisión interna que permita diferenciar claramente a la mayoría frente a los grupos marginales. Debe existir un enemigo capaz de invitar a la mayoría a cohesionarse en su contra, a identificarse a raíz de la exclusión del "otro" (Uribe 2012, 81).

1 Siguiendo a Díaz (2004), las víctimas han asumido nuevos roles en el derecho penal: son las demandas de las víctimas, muchas veces potenciales o arquetípicas, las que orientan el debate sobre la política criminal y se entiende que la relación entre el delincuente y la víctima es un juego de suma cero.

Esta obra está bajo una Licencia Creative Commons

Atribución-NoComercial-SinDerivar 4.0 Internacional, IIJ-UNAM.

Boletín Mexicano de Derecho Comparado, núm. 155, mayo-agosto de 2019, pp. 1047-1079. 
Partiendo de ese concepto, el autor considera que el populismo punitivo no ha existido en Colombia, ${ }^{2}$ pues las particulares condiciones del país, tales como el conflicto armado, las instituciones débiles, la lógica de la emergencia, entre otros factores, han sido los que en realidad han llevado a la implantación de un "derecho penal autoritario". De ese modo, el autor sostiene que posiblemente habrá algún caso en el que podría hablarse de populismo punitivo, como el recurso a las sensibilidades sociales con relación a los delitos sexuales en menores (véase Vélez 2007), pero que realmente no dan cuenta de transformaciones políticas como las que se dieron en Estados Unidos e Inglaterra como el paso del Estado de bienestar al Estado neoliberal, el cambio del ideal resocializador, etcétera.

Quizá en Colombia no ocurrieron tales transformaciones políticas porque nunca se materializó un Estado de bienestar y jamás se tomó en serio el proceso de resocialización del delincuente; sin embargo, los presupuestos señalados se evidencian en el diseño del sistema penal colombiano. De igual forma, si bien el derecho penal coincide y muchas veces adquiere el carácter autoritario, no es el único marco que explica el populismo punitivo. Los presupuestos que expone el autor se relacionan con otras tendencias de expansión irracional del derecho penal, como el derecho penal del enemigo (Zaffaroni 2011) y la justicia penal de excepción (Iturralde 2010). Ahora bien, estas tendencias no son necesariamente excluyentes con el populismo punitivo, pero tampoco lo explican plenamente.

Así, como se verá más adelante, la lucha contra las drogas es considerada por García $(2014,162)$ como una clara manifestación de populismo punitivo, que sirve como mecanismo de control contra un grupo determinado de ciudadanos, generalmente lo más pobres, y como aparato simbólico que da lugar a la construcción de un "enemigo" colectivo, en contra de quien la población se une alrededor de sus gobernantes. La lucha contra las drogas también ha sido un ejemplo de derecho penal del enemigo y justicia penal de excepción, como también lo explica Iturralde (2010).

A pesar de las notables diferencias, se debe reconocer que en Colombia, como en otros países latinoamericanos, también han influido el neoliberalismo y neoconservadurismo, y con ello, la exclusión y la desigualdad. Esto, como en los países europeos o norteamericanos, se ha visto reflejado

2 Para el autor, en Colombia ha existido un populismo hobbesiano. Para más información, véase Uribe $(2012,97)$. 
en el derecho penal en dos aspectos que se han ido profundizando: una justicia penal ineficaz ante altos niveles de criminalidad y la implementación de medidas penales de carácter represivo para hacer frente a problemas sociales. Ahora bien, no puede desconocerse una diferencia esencial concerniente a la debilidad estatal, la inestabilidad de la democracia y la carencia de legitimidad de los regímenes políticos en los países latinoamericanos, que han terminado por incrementar la violencia mediante acciones del mismo Estado (Iturralde 2007a, 113-116).

El hecho de que sociedades se caractericen por una desigualdad estructural y particularmente arraigada incide en la formación del derecho penal. De acuerdo con Wilkinson y Pickett (2009, 179-180), es posible observar que, en las sociedades más desiguales, la distinción ellos-nosotros, la desconfianza y el temor al delito encuentran mayor arraigo en la población. En estos casos, el sistema penal responde a presiones políticas y mediáticas, por lo que el endurecimiento de los castigos constituye una manera de ofrecer "imagen de firmeza" frente a la sociedad, en lugar de atender a cuestiones como la efectividad en la prevención del delito o la rehabilitación de quien delinque.

En ese sentido, también son distintas las actitudes que las sociedades, con escisiones o desigualdades notables, asumen hacia la delincuencia. Cavadigno y Dignan (2006) señalan que existe una relación entre la política económica de un Estado y la manera en que funciona el sistema penal (nivel de severidad punitiva, número de personas en prisión, etcétera). Así, en sociedades con una mayor desigualdad económica existe un mayor aumento de la severidad penal, pues las sociedades más igualitarias no sólo son más incluyentes socialmente, además intentan no ubicar al delincuente en un nivel de desigualdad mayor. De ese modo, las sociedades neoliberales, con un ethos individualista, tienden a generar más exclusión social, mayor desigualdad y a considerar que el individuo que delinque es totalmente responsable de sus acciones. Mientras tanto, las sociedades socialdemócratas corporativistas, con un ethos comunitario, tienden a generar mayor inclusión social, mayor igualdad y a considerar que la comunidad tiene la responsabilidad de resocializar al individuo que delinque. Se desarrollan entonces algunas tendencias a nivel mundial: las sociedades que se orientan hacia el neoliberalismo adoptan un sistema punitivo más severo; las sociedades con tendencia hacia la social democracia o el corporativismo adoptan un sistema penal menos severo.

Esta obra está bajo una Licencia Creative Commons

Atribución-NoComercial-SinDerivar 4.0 Internacional, IIJ-UNAM.

Boletín Mexicano de Derecho Comparado, núm. 155, mayo-agosto de 2019, pp. 1047-1079. 
Lo antedicho se contrasta con la historia latinoamericana, que está caracterizada por lo que se anticipó, como la "emergencia crónica", donde el "enemigo" ha mutado constantemente y con ello, ha permitido robustecer el aparato represivo del Estado, usualmente por medio de la utilización nada ponderada de los Estados de excepción. La continua y casi ineludible declaración de emergencia es un factor que se materializa en una justicia penal de excepción, particularmente autoritaria y restrictiva de las garantías y los derechos de los perseguidos penalmente y de la sociedad en general, que llegó a hacer tránsito a la legislación permanente en muchos de los casos (Iturralde 2010).

La justicia penal de excepción desarrollada en Colombia se orientó siempre, en el discurso político declarado, al sometimiento de los criminales que el Gobierno definió como los más peligrosos, como la mayor amenaza social y estatal, permitiendo en algunos casos, limitar la alteridad o penalizar movimientos sociales o algunas demandas populares. La supuesta necesidad imperiosa de proteger la existencia del Estado y la ciudadanía misma de estos criminales justificaba la utilización de mecanismos de control y tecnologías de castigo excepcionales, que implicaban una ruptura tanto con el Estado de derecho, como con los principios esenciales de la democracia liberal. En pocas palabras, la lógica operativa bajo la cual ha funcionado la justicia penal de excepción "es que mientras los enemigos de los órdenes políticos y sociales no sean derrotados no será posible otorgar a los ciudadanos el goce completo de sus derechos y libertades" (Iturralde 2010, 57). ${ }^{3}$

Durante los distintos estados de excepción, se hizo recurrente la utilización de mecanismos restrictivos similares, sin importar la ineficacia instrumental de Estado. Este hecho también obedecía a una lógica distinta, a partir de la cual los gobiernos podían conseguir réditos políticos. Así, las reformas punitivas, además de ser fácilmente implementadas, pues se agotaban en la emisión de una ley y su comunicación, generan un "impacto social y simbólico profundo, es decir, crean la representación en el colectivo de un Estado fuerte que adopta las medidas requeridas para en-

3 Se aplica entonces el modelo del derecho a la seguridad propuesto por Baratta (2001), en el cual se da primacía al derecho a la seguridad de los de los "grupos socialmente fuertes con respecto de riesgos provenientes de grupos carentes del disfrute de derechos fundamentales", es decir, con respecto a la seguridad de los derechos. 
frentar un enemigo todopoderoso, que varía de una época a otra, según las circunstancias" (Iturralde 2010, 58). De ese modo, el sistema penal de excepción no sólo respondía a la crisis ocasionada por la violencia, también constituye un instrumento político que le ayuda a la elite política a disminuir la presión que recae sobre sí, y a legitimar su dominio (Iturralde 2010, 58).

El recurso al populismo del miedo, como lo denomina Chevigny (2003, 83 y 91), ha trasladado la atención y la agenda legislativa hacia la preocupación por la criminalidad y por la seguridad, y ha permitido dejar a un lado otras demandas sociales. Sin embargo, los mecanismos punitivos utilizados en los estados de excepción eran similares, aunque el enemigo era un factor dinámico, construido por el discurso político dominante. Así, Iturralde (2010) identifica los orígenes de la justicia penal de excepción en el gobierno de Rafael Nuñez (1886), en el cual el enemigo era la oposición al régimen, en el gobierno de Miguel Abadía Méndez (1928), el enemigo eran los huelguistas que protagonizaron conflictos laborales con la United Fruit Company. Con la instauración del Frente Nacional, la justicia penal de excepción se consolidó en torno a un enemigo distinto, los cuales serían los movimientos obreros, estudiantiles y sociales que organizaban las distintas protestas sociales por la precariedad de las condiciones de vida de las clases menos favorecidas en el país. Con el surgimiento y expansión de los grupos armados, estos también pasaron a ser objeto de la persecución penal de excepción. Al finalizar el Frente Nacional, el narcotráfico cobra fuerza como el enemigo central en torno al cual se estructura el discurso penal de excepción por décadas.

En el caso de la guerra contra las drogas, se hace particularmente visible el populismo punitivo en el marco de la justicia penal de excepción. El propósito no era la derrota del narcotráfico, pero la reforma legal se tomó como medio para comunicar un valor, simbolizar una meta, y crear una representación en la opinión pública (García 2014, 170). ${ }^{4}$

Paradójicamente, durante el gobierno siguiente a la guerra contra las drogas, no sólo se creó la Constitución de 1991, cargada de derechos y garantías, sino que, también, se dio la integración del sistema penal de

\footnotetext{
4 La criminalización de la dosis personal en el marco de la lucha contra las drogas también puede ser considerada como un ejemplo de populismo punitivo (Londoño y Restrepo 2011).
} 
excepción en el nuevo ordenamiento jurídico. La normalización de la justicia penal de excepción obedecía a varias causas, entre ellas, la necesidad transmitir una "imagen engañosa de poder" con el fin de "difuminar y encubrir las crisis políticas producto de su incapacidad práctica de reducir la violencia y retomar el control del orden público" (Iturralde 2010, 149).

Durante el gobierno de Gaviria y el de Samper, el enemigo principal continuó siendo el narcotráfico, y junto a él, los grupos armados ilegales. Durante el gobierno del conservador Andrés Pastrana, los esfuerzos se centraron también en el narcotráfico, con el apoyo de los Estados Unidos mediante el Plan Colombia, y se desarrolló el proceso de paz con las FARG. ${ }^{5}$ Ante el fracaso de este proceso, el gobierno de derecha de Álvaro Uribe elaboró un discurso alrededor de las Fuerzas Armadas Revolucionarias de Colombia (FARG-EP) como principal enemigo, el cual fue categorizado como terrorista y narcotraficante, y desarrolló el proceso de paz con las Autodefensas Unidas de Colombia (AUC), con quien manejó un discurso menos intenso y negoció la Ley de Justicia y Paz, "como imagen invertida de las formas del sistema penal de excepción” (Iturralde 2010). Así, la seguridad democrática fue una política de doble vía, que ofrecía un tratamiento diferenciado para las guerrillas y los paramilitares. Para las primeras, se negó la existencia del conflicto armado y la condición de delincuentes políticos, por lo cual se restringieron sus condiciones de negociación; a los segundos, se les reconoció estatus político y se les brindó un trato legal favorable (Iturralde, 2010).

En ese periodo, la justicia penal de excepción sirvió para cubrir los vínculos entre las elites políticas y económicas del país y el paramilitarismo, protegiendo el statu quo: un modelo autoritario y excluyente (Iturralde 2010, 295). En definitiva, el sistema penal de excepción, siguiendo a Schmitt, funcionó bajo la lógica amigo/enemigo, en la que prevalecen los intereses de los poderosos, bajo el ejercicio de una política que busca eliminar a los indeseables y mantener el orden vigente. El gobierno autoritario aprovechó el temor social, el miedo irracional que el mismo Estado creó a través del uso ilegítimo y expansivo de la violencia, y que sirve

5 Sobre la justicia penal de excepción en los gobiernos de Pastrana y Uribe, véase también Iturralde (2007b). 
como soporte para garantizar la obediencia social y la cohesión en contra del enemigo construido ${ }^{6}$ (Iturralde 2003).

\section{UNA PROPUESTA PARA RELEER EL POPULISMO PUNITIVO}

Como se evidenció, el expansionismo penal se explica a partir de múltiples causas, propias y particulares de su contexto, entre las cuales se puede destacar la concurrencia con el derecho penal del enemigo y la reforma penal de excepción. El populismo punitivo, en el marco teórico abordado, ha sido caracterizado por: a) la expansión irracional del derecho penal (sea a través la creación de nuevos delitos, el aumento de las penas, la creación de agravantes, la exclusión de beneficios y subrogados, etcétera), b) mediante procesos de creación de normas jurídicas altamente politizados - en los cuales no hay lugar para los conceptos e investigaciones empíricas de grupos de expertos o especialistas en el área, y no se tiene en cuenta la verdadera efectividad que las normas puedan tener para cumplir con el fin que dicen buscar (la prevención de los delitos)-, c) que dicen responder a la necesidad de prevenir la comisión de delitos, pero que en realidad obedecen a lo que demanda la opinión pública, a la "necesidad" de reivindicar a las víctimas o a la satisfacción de los sentimientos de algunos sectores de la sociedad, como el miedo, la sed de retaliación, etcétera, con la posibilidad de sacar provecho político de los efectos simbólicos de la pena, con la finalidad de generar un doble beneficio para el gobernante: el efecto simbólico de apaciguamiento de la población y la posible obtención de réditos políticos.

A la luz de los aportes previamente citados, a continuación, presentaremos la siguiente propuesta, tomando como ejemplos de populismo punitivo el feminicidio, el aborto, las quemaduras con ácido y la penalización de conductores en estado de embriaguez. Así, se encontrarán varios insumos que anticiparon los autores citados, y se propondrá su medición, a partir de la propuesta anunciada. De este modo, se establecerá en una

6 En ese sentido, Zaffaroni (2011, 13 y 150) señala que "el enemigo de la sociedad o extraño, es decir, el ser humano considerado como ente peligroso o dañino y no como persona con autonomía ética, desde la teoría política, sólo es compatible con un modelo de estado absoluto total". Siguiendo a Schmitt, reitera que "el enemigo no viene ónticamente impuesto, no es un dato de hecho que se impone al derecho, sino que es políticamente señalado. Aunque existan mitos anteriores, se reconoce que se señala al enemigo porque conviene señalarlo".

Esta obra está bajo una Licencia Creative Commons

Atribución-NoComercial-SinDerivar 4.0 Internacional, IIJ-UNAM.

Boletín Mexicano de Derecho Comparado, núm. 155, mayo-agosto de 2019, pp. 1047-1079. 
calificación binaria de 0 a 1 o una escala de indicadores, si el delito - $\mathrm{O}$ el intento para consagrarlo - fue el resultado de alguno de los siguientes factores: 1) expansión irracional del sistema penal, 2) de la politización del proceso legislativo, 3) desatendieron la voz de expertos, 4) explotaron la sensibilidad social producida por la desigualdad, 5) revelan una escisión social interna y 6) son normas con una alta ineficacia.

Factor 1. Desatiende la voz de expertos

Para medir el factor se propone un indicador de eficacia que se calcula como el número de propuestas atendidas sobre el número de propuestas planteadas por el Consejo de Política Criminal, así:

$$
F_{1}=\frac{P A}{P P}
$$

Donde:

\section{$P A=\#$ de propuestas atendidas}

$P P=\#$ de propuestas planteadas por el Consejo de Política Criminal

Para medir este factor se propone la siguiente escala:

TABLA 1

ESCALA DE CALIFICACIÓN DEL FACTOR 1

\begin{tabular}{|c|c|c|}
\hline Proporción & Puntaje & Nivel de populismo \\
\hline$[0 ; 0,25)$ & 1 & Alto \\
\hline$[0,25 ; 0,5)$ & 0,75 & Medio \\
\hline$[0,5 ; 0,75)$ & 0,5 & Bajo \\
\hline$[0,75 ; 1)$ & 0 & Nulo \\
\hline
\end{tabular}

FUENTE: elaborado por los autores.

Valores bajos resultantes en $\mathrm{F}_{1}$ representan niveles altos de populismo en este factor. 
Factor 2. Alta ineficacia de la norma

Para medir el factor se propone un indicador de eficacia que se calcula como el número de condenas sobre el número de ocurrencias del delito, así:

$$
F_{2}=\frac{C}{O}
$$

Donde:

\section{$C=\#$ de condenas por este delito \\ $0=\#$ de ocurrencias del delito}

Para medir este factor se propone la siguiente escala:

TABLA 2

ESCALA DE CALIFICACIÓN DEL FACTOR 2

\begin{tabular}{|c|c|c|}
\hline Proporción & Puntaje & Nivel de populismo \\
\hline$[0 ; 0,25)$ & 1 & Alto \\
\hline$[0,25 ; 0,5)$ & 0,75 & Medio \\
\hline$[0,5 ; 0,75)$ & 0,5 & Bajo \\
\hline$[0,75 ; 1)$ & 0 & Nulo \\
\hline
\end{tabular}

NOTA: elaborado por los autores.

Valores bajos resultantes en $\mathrm{F}_{2}$ representan niveles altos de populismo en ese factor.

Factor 3. Expansión irracional del derecho penal

Para medir este factor se deben revisar los siguientes elementos que evidencian populismo, en los contenidos de la norma:

1) Creación de nuevo delito.

2) Aumento de penas.

3) Creación de agravantes.

4) Exclusión de beneficios y subrogados.

Esta obra está bajo una Licencia Creative Commons

Atribución-NoComercial-SinDerivar 4.0 Internacional, IIJ-UNAM.

Boletín Mexicano de Derecho Comparado, núm. 155, mayo-agosto de 2019, pp. 1047-1079. 
Cada uno de estos elementos será comprendido como una variable binaria así:

$$
E_{i}\left\{\begin{array}{c}
1 \text { si el elemento } i \text { está presente } \\
0 \text { en el caso contrario }
\end{array}\right\}
$$

Donde:

$E_{1}=$ Creación de nuevo delito.

$E_{2}=$ Aumento de penas.

$E_{3}=$ Creación de agravantes.

$E_{4}=$ Exclusión de beneficios y subrogados.

Para medir este factor se propone un indicador de eficacia que se calcula como el número de condenas sobre el número de ocurrencias del delito, así:

$$
F_{3}=\frac{\sum_{i=1}^{4} E_{i}}{4}
$$

Donde:

$$
E_{i}\left\{\begin{array}{c}
1 \text { si el elemento } i \text { está presente } \\
0 \text { en el caso contrario }
\end{array}\right\} \quad \text { con } i=\{1 ; 2 ; 3 ; 4\}
$$

Para medir este factor se propone la siguiente escala:

TABLA 3

ESCALA DE CALIFICACIÓN DEL FAGTOR 3

\begin{tabular}{|c|c|}
\hline Puntaje & Nivel de populismo \\
\hline 1 & Alto \\
\hline 0,75 & Medio \\
\hline 0,5 & Bajo \\
\hline 0,25 & Nulo \\
\hline
\end{tabular}

FUENTE: elaborado por los autores.

Valores altos resultantes en $\mathrm{F}_{3}$ representan niveles altos de populismo en ese factor. 
Factor 4. Politización del proceso legislativo

Para medir este factor se deben revisar los siguientes elementos sociales que evidencian populismo:

1) Existe una víctima o victimario emblemático.

2) Se han realizado marchas o movilizaciones (recolección de firmas).

3) Amplio cubrimiento de noticias.

Cada uno de estos elementos será comprendido como una variable binaria así:

\section{$S_{i}\left\{\begin{array}{c}1 \text { si el elemento } i \text { está presente } \\ 0 \text { en el caso contrario }\end{array}\right\}$}

Donde:

$S_{1}=$ Existe una víctima o victimario emblemático.

$S_{2}=$ Se han realizado marchas o movilizaciones (recolección de firmas).

$S_{3}=$ Amplio cubrimiento de noticias.

Para medir este factor se propone la siguiente escala:

TABLA 4

PONDERAGIÓN DE LOS ELEMENTOS SOCIALES QUE DEMUESTRAN UNA POLITIZAGIÓN DEL PROGESO LEGISLATIVO

\begin{tabular}{|c|c|}
\hline Elemento & Peso $(w)$ \\
\hline$S_{1}$ & 0,25 \\
\hline$S_{2}$ & 0,5 \\
\hline$S_{3}$ & 0,25 \\
\hline Total & 1 \\
\hline
\end{tabular}

FUENTE: elaborado por los autores.

Para medir este factor se propone un indicador de eficacia que se calcula como la suma de productos de la existencia del elemento social por su peso, así: 


$$
F_{4}=\sum_{i=1}^{3} S_{i} * W_{i}
$$

Donde:

$$
\begin{gathered}
S_{i}\left\{\begin{array}{c}
1 \text { si el elemento } i \text { está presente } \\
0 \text { en el caso contrario }
\end{array}\right\} \quad \text { con } i=\{1 ; 2 ; 3\} \quad y \\
W_{i}=\text { Peso del elemento } i ; \quad \text { con } i=\{1 ; 2 ; 3\}
\end{gathered}
$$

Para medir este factor se propone la siguiente escala:

TABLA 5

ESCALA DE GALIFICACIÓN DEL FACTOR 4

\begin{tabular}{|c|c|}
\hline Puntaje & Nivel de populismo \\
\hline$\geq 0,75$ & Alto \\
\hline 0,5 & Medio \\
\hline 0,25 & Bajo \\
\hline 0 & Nulo \\
\hline
\end{tabular}

FUENTE: elaborado por los autores.

Valores altos resultantes en $\mathrm{F}_{4}$ representan niveles altos de populismo en ese factor.

Factor 5. Sensibilidad social producida por desigualdad

Para medir este factor se debe contestar la siguiente pregunta: ¿hay evidencia de desigualdad y escisión social reflejada en la reforma penal?

La respuesta a esta pregunta es tomada como una variable binaria así:

$$
F_{5}\left\{\begin{array}{c}
1 \text { si hay evidencia de desigualdad } \\
0 \text { en el caso contrario }
\end{array}\right\}
$$

$\mathrm{El}$ valor 1 resultantes en $\mathrm{F}_{5}$ representa populismo en ese factor. 
Factor 6. Escisión social interna

Para medir este factor se debe contestar la siguiente pregunta: ¿existe un enemigo común identificado en la reforma penal?

La respuesta a esta pregunta es tomada como una variable binaria así:

$$
F_{6}\left\{\begin{array}{c}
1 \text { si existe un enemigo común } \\
0 \text { en el caso contrario }
\end{array}\right\}
$$

El valor 1 resultantes en $\mathrm{F}_{6}$ representa populismo en ese factor

\section{Operacionalización de los factores}

El nivel de populismo penal se estima como la sumatoria de los seis factores de populismo, así:

$$
P P=\sum_{i=1}^{6} F_{i}
$$

Para identificar el nivel de populismo, se propone la siguiente escala:

TABLA 6

ESCALA DE CALIFICACIÓN

\begin{tabular}{|c|c|}
\hline Valor de PP & Nivel de populismo \\
\hline$(4,5 ; 6]$ & Alto \\
\hline$(3 ; 4,5]$ & Medio \\
\hline$(1,5 ; 3]$ & Bajo \\
\hline$[0 ; 1,5]$ & Nulo \\
\hline
\end{tabular}

FUENTE: elaborado por los autores.

A continuación, se presentarán los resultados de la aplicación de estos factores a los delitos de feminicidio, el aborto, las quemaduras con ácido y la penalización de conductores en estado de embriaguez, y demostrar de esta forma, la utilidad del modelo utilizado. El primer caso seleccionado, el tipo penal de feminicidio (artículo 104A del Código Penal colombiano) fue creado mediante la Ley 1761 de 2015, también conocida como la Ley 
Rosa Elvira Cely. La ley recibió el nombre de una mujer que fue víctima de un homicidio extremadamente violento, cuya atrocidad lo llevó a ser mediatizado (Semana 2012) y a conmocionar a amplios sectores del país. Los hechos ocurrieron el 24 de mayo de 2012, a menos de un mes de que acabara la legislatura; pero para el 1o. de agosto ya se presentaba en el Congreso una iniciativa (proyecto de ley $49 / 12)^{7}$ para penalizar el feminicidio. Este primer proyecto fue archivado por tránsito de legislatura el 20 de junio de 2013. Posteriormente, el 25 de octubre de 2013 se presentó un nuevo proyecto de ley (107/13 Senado, 217/14 Cámara), que fue sancionado como ley el 7 de julio de 2015.

Este delito revela la expansión irrazonable del derecho penal, pues antes de la creación del tipo penal, los casos en que se ocasionaba la muerte a una mujer, por el hecho de ser mujer, constituían homicidio agravado y tenían una pena entre 400 y 600 meses (artículo 103, Numeral 11 del Código Penal colombiano). Esta causal de agravación es derogada y en su lugar se crea el tipo penal de feminicidio con una pena entre 200 y 500 meses, y con sus propias causales de agravación (entre ellas se incluyen algunas de las causales de agravación para el homicidio) para las cuales se establece una pena entre 500 y 600 meses. También se añadió una causal de agravación a las lesiones personales, entre otros cambios. La redacción misma del delito permite constatar la irrazonabilidad de la expansión del derecho penal, pues el tipo que alcanza a cobijar una gran cantidad de conductas, incluso algunas que no se cometen contra la mujer por el hecho de serlo.

Este delito también da cuenta de un proceso politizado y que desconoció las voces de expertos. En efecto, con la Ley 1761 de 2015, el Congreso desconoció el concepto desfavorable del Consejo Superior de Política Criminal, en el cual no sólo reiteró que se debían adoptar medidas no penales para poder reducir de manera efectiva la violencia de género,

7 En la exposición de motivos del proyecto destacaba el caso de Rosa Elvira Cely como argumento a favor de la penalización del feminicidio: "Hechos de luto nacional como el cruel feminicidio, violación, tortura y empalamiento de Rosa Elvira Cely recientemente ocurrido, visibilizan y ponen en evidencia las formas más crueles de violencia basada en género, que compelen a que el Congreso de la República adopte una ley que penalice ejemplarmente el feminicidio y todas las formas de violencia contra las mujeres, por el hecho de ser mujeres" (Congreso de la República de Colombia, 2012, Gaceta 488 del 3 de agosto). 
sino que además se señalaron los problemas de redacción que tenían las disposiciones normativas. ${ }^{8}$

La creación del delito del feminicidio también revela una explotación de sensibilidades sociales derivadas de desigualdades, en particular, el acto de atrocidad cometido contra Rosa Elvira Cely, que levantaron sus voces para apoyar el proyecto, para reclamar justicia y para agradecer una vez que éste fue sancionado. ${ }^{9}$

En este sentido, el mismo Consejo Superior de Política Criminal opinó: "La regulación propuesta está llamada a cumplir con una función simbólica, que no propone una respuesta eficiente a la violencia contra la mujer..." (Congreso de la República, 2014, Gaceta 693 del 10 de noviembre), una función de apaciguamiento de las masas que demandaban acciones estatales para prevenir nuevas víctimas.

La implementación de este delito también da cuenta de una profunda escisión social interna, derivada por la notable desigualdad económica y diversos imaginarios machistas que trazan una diferencia entre hombres y mujeres. Por otra parte, la ineficacia instrumental en este caso resulta notoria, teniendo en cuenta que, a diciembre de 2016, sólo se habían impuesto ocho sentencias condenatorias y se han decretado 46 medidas

8 El ente asesor de la política criminal colombiano advirtió que: "La problemática de la violencia de género de la que resultan víctimas las mujeres, merece especial atención por parte del Estado colombiano. Sin embargo, enfocar la intervención del mismo en una respuesta netamente penal, además de exonerar a otros gestores de las políticas públicas, buscaría reprimir este tipo de comportamientos solo cuando lleguen a su máxima expresión, es decir, cuando se cause la muerte de una mujer, olvidando que, la violencia que se ejerce contra ellas no es solo la feminicida, y que respecto de ese otro tipo de violencias las cifras revelan un panorama mucho más preocupante. El Código Penal, por su parte, además del referido numeral undécimo del artículo 104, consagra disposiciones, en la parte general, que están llamadas a condicionar la parte especial, en las que se entienden introducidas perspectivas de protección de género, o se identifican algunas situaciones con las que pretende incluir con el proyecto de ley... Por lo anterior no es cierto que exista un panorama de desprotección penal a las mujeres como grupo vulnerables dentro de la sociedad. Debe tenerse en cuenta que la redacción de la propuesta legislativa vulnera los principios de legalidad, taxatividad, tipicidad y que, de quererse incluir la conducta de feminicidio de manera autónoma, la misma se debería reformular, pues, tal como se consagra, se incluyen conductas ajenas a la violencia de género, reduce la pena, elimina una causal de agravación para las lesiones personales y reduce el grado de protección constitucional" (Congreso de la República, 2014, Gaceta 693 del 10 de noviembre).

9 Véase, por ejemplo, El Espectador (2012) y El Tiempo (2015). 
preventivas en procesos penales abiertos, aún pendientes de resolución definitiva, frente a más de 4,700 casos estimados de feminicidio (véase, por ejemplo, Fiscalía General de la Nación 2017, en adelante FGN).

La misma suerte "populista" seguiría la creación del tipo penal sobre quemaduras y lesiones con agentes químicos, ácido y/o sustancias similares (artículo 116 A del Código Penal), que fue creado mediante la Ley 1773 del 2016. Esta ley también lleva el nombre de Natalia Ponce, una mujer que fue víctima de un ataque con ácido el 27 de marzo de 2014. Se trató de un caso altamente mediatizado, en el que el país ha estado al tanto de los distintos progresos que ha tenido la salud de esta víctima emblemática y rechazado vehementemente los ataques de esta naturaleza. Antes de que el caso tuviera lugar, el último intento para penalizar ese tipo de conducta de manera autónoma había sido en 2012, mediante el proyecto 197 de 2012 Senado, aunque en febrero de 2013 se había sancionado la Ley 1639 de 2013, por medio de la cual se añadió un inciso a la disposición que regula la pena de lesiones personales por deformidad, en el cual se agravaba la pena cuando ésta fuese ocasionada mediante "cualquier tipo de ácidos; álcalis; sustancias similares o corrosivas".

Durante el mes que siguió al caso de Natalia Ponce, en el Congreso se presentaron los tres proyectos de ley que buscaban penalizar la conducta mediante un tipo autónomo: 183 de 2014 Senado; 191 de 2014 Senado, y 66 de 2014 Cámara. También se presentó un proyecto, que buscaba considerar la conducta como parte del tipo penal de tortura (proyecto 185 de 2014 Senado). Esa legislatura acabó sin que ninguno de los proyectos se aprobara, pero el 20 de julio, al inicio de la siguiente legislatura, se presentaba una iniciativa que culminaría en la aprobación de la Ley 1773 de 2016.

Como se mencionó, las lesiones personales ocasionadas por ácido y sustancias químicas supone una inflación irracional del sistema penal, que crea el tipo penal especial, a pesar de que dicha conducta se encuadraba en el tipo penal de lesiones personales, agravadas por el uso de ácidos, álcalis, sustancias similares o corrosivas, que dañan o destruyen el tejido humano al entrar en contacto con él, cuya pena era de 72 a 126 meses (artículo 113 del Código Penal, inciso derogado por la Ley 1773 de 2016), ${ }^{10} \mathrm{y}$

10 El inciso derogado fue creado mediante la Ley 1639 de 2013, cuyo proceso legislativo también permite ejemplificar el populismo punitivo, tal como lo explica Díaz (2014). 
que con la citada norma, pasó a tener una pena de 150 a 240 meses, agravada si llegara a causar deformidad o daño permanente - de 251 a 360 meses - ; todo esto con la posibilidad de aumentar en una tercera parte si el daño afecta la cara, lo que implicaría un máximo de pena de hasta 470 meses. De ese modo, el delito podría llegar a tener una pena mayor que el homicidio. Además, la conducta tipificada fue incluida en el listado de delitos a los cuales se les excluye beneficios y subrogados penales (artículo 68A del Código Penal).

En el proceso legislativo también se ignoraron las voces expertas, en la medida en que el Congreso desconoció el concepto desfavorable del Consejo Superior de Política Criminal (2015), que propuso revisar previamente los resultados que ha arrojado la legislación vigente en materia de reducción del delito y protección de los derechos fundamentales de las víctimas, entre otros argumentos.

Este proyecto de ley fue politizado, y como se señaló, emerge a partir de una "víctima emblemática", el caso de Natalia Ponce, que contó con un seguimiento notable por parte de la opinión pública, lo cual permitió que la ciudadanía conociera el proceso de recuperación de la víctima, al tiempo que apoyaba el proceso legislativo (véase, por ejemplo, El Tiempo 2014). Adicionalmente, el mismo Congreso, en la exposición de motivos del proyecto, reivindicó a las víctimas y declaró la necesidad de "[rechazar] este tipo de crímenes que afectan de manera especial a la mujer, y estipule fuertes sanciones para quienes se atreven a llevar a cabo la violencia con ácido" (Congreso, 2014, Gaceta 366 del 24 de julio).

Posteriormente, frente al concepto desfavorable del Consejo Superior de Política Criminal, el Congreso centró su argumento en una apelación al pueblo, afirmando incluso que el sistema penal "está privilegiando los derechos de quienes cometen crímenes en detrimento de sus propios derechos y libertades, de su seguridad personal y la de su familia" (Congreso de la República de Colombia, 2015, Gaceta 859 del 28 de octubre).

Este proyecto de ley también da cuenta de una profunda escisión social interna, producto de la estructural violencia de género. En efecto, de la mano de la ineficacia instrumental que ha tenido este delito, se puede constatar un abismo entre el número de víctimas denunciantes y el número efectivo de condenados, pues se estima que, en Colombia, entre 2004 y 2016, hay más de 954 mujeres víctimas de quemaduras con ácido, y sólo ha habido ocho personas condenadas a la fecha (FGN 2017).

Esta obra está bajo una Licencia Creative Commons

Atribución-NoComercial-SinDerivar 4.0 Internacional, IIJ-UNAM.

Boletín Mexicano de Derecho Comparado, núm. 155, mayo-agosto de 2019, pp. 1047-1079. 
El tercer ejemplo que se ha utilizado en este documento es la aprobación de la Ley 1696 de 2013, resultado de varios proyectos, que pretendían regular penalmente la conducción en estado de embriaguez. El proyecto 28 de 2012 Cámara (Congreso de la República de Colombia, Gaceta 465 de 2012), que se acumuló en el 80 de 2012 Cámara/ 28 de 2012 Senado (Congreso de la República de Colombia, Gaceta 518 de 2012), fue archivado por tránsito de legislatura en junio de 2013.

Sin embargo, el 12 de julio de 2013, Fabio Andrés Salamanca, un joven que conducía en estado de embriaguez una camioneta de lujo, ocasionó la muerte de dos jóvenes y dejó paralítico a un taxista. Los hechos fueron mediatizados y conmocionaron al país (Semana 2013). El 20 de julio de 2013, al inicio de la legislatura, se radicó en el Congreso el proyecto 16 de 2013 Senado que, irracionalmente, proponía tipificar el homicidio doloso por conducir en estado de embriaguez estableciendo una presunción objetiva del dolo ${ }^{11}$ (Congreso de la República de Colombia, Gaceta 573 de 2013).

A los pocos días, el 8 de agosto de 2013, se radicó un nuevo proyecto - el 47 de 2013 Senado - que buscaba establecer una medida policiva consistente en arresto entre 1 y 10 días para los conductores en estado de embriaguez (Congreso de la República de Colombia, Gaceta 599 de 2013). Finalmente, ambos proyectos fueron acumulados en el proyecto de ley 117 del 2013 Cámara/90 de 2013, Senado (Congreso de la República de Colombia, Gaceta 749 de 2013), radicado el 16 de septiembre de ese año. Este último culminaría con la aprobación de la Ley 1696 de 2013 en diciembre del mismo año, cuatro meses después de que se presentara la iniciativa. ${ }^{12}$ La mencionada ley añadió una nueva circunstancia de agravación al tipo penal de homicidio culposo (artículo 110, numeral

11 Específicamente, el proyecto establecía que "se entenderá que incurre en homicidio doloso todo agente que al conducir vehículo automotor bajo el influjo de bebidas embriagantes, o sustancias psicotrópicas, ocasione siniestro de tránsito que tenga como resultado la muerte de personas, si hecha la prueba para medir el nivel de las bebidas embriagantes, o sustancias psicotrópicas en el organismo se establece tercer grado" (Congreso de la República de Colombia, Gaceta 573 de 2013).

12 De acuerdo con Díaz (2004), los actores encargados de crear el derecho brindan un acceso privilegiado a las demandas de la opinión pública, las víctimas y la sociedad, evadiendo los controles burocráticos democráticos. En ese sentido, se acelera el proceso legiferante y se le quita importancia al debate parlamentario; aludiendo a la urgencia de la alarma social o al consenso social se dejan de lado los espacios en los cuales podían opinar 
6 del Código Penal), consistente en un aumento de la pena en los casos en que la persona comete el homicidio culposo "conduciendo en estado de alcoholemia mayor o igual a 1 grado o bajo el efecto de alguna droga o sustancia que produzca dependencia física o síquica, y ello haya sido determinante" para la ocurrencia del hecho.

En este caso constatamos un aumento irracional del sistema penal, debido a que se incluía un agravante en el delito. El texto previo a la reforma establecía una pena que se encuentra entre los 32 y los 108 meses (artículo109 del Código Penal colombiano), mientras que, con la agravante consagrada en la mencionada ley, la pena se aumenta de las dos terceras partes al doble (artículo 110 del Código Penal colombiano), lo cual supondría una pena entre 64 y 180 meses. De igual forma, el proceso de creación de la Ley 1696 de 2013 desconoció las voces de expertos, pues ignoró el concepto desfavorable del Consejo Superior de Política Criminal. Durante uno de los debates en el Congreso, varios senadores se refirieron al concepto negativo del ente asesor, y expresaron lo siguiente:

Claro, aquí nosotros nos las damos de juristas y claro que el concepto del Consejo de Política Criminal y nos critica que porque nosotros estamos legislando de acuerdo a los acontecimientos y que hay que legislar en este país como diga el consejo de política criminal. Yo les pregunto, señores, fuera de los parlamentarios que hacen hoy parte de ese consejo de política criminal, ¿quién ha sido elegido popularmente? Si son unos juristas muy eminentes que yo respeto mucho, pero ellos lo único que hacen es emitir conceptos, conceptos, ayudas acá para que tomemos decisiones desde el punto de vista jurídico adecuadas, pero no son de carácter obligatorio y vinculante (Congreso de la República de Colombia, Gaceta 19 de 2014).

En el mismo sentido, el proceso legislativo se vio politizado, y los congresistas argumentaron, durante el debate, que la reforma penal respondía a la opinión pública, las víctimas, la ciudadanía, y que la importancia de la ley radicaba en su efecto simbólico. ${ }^{13}$

los expertos. De ese modo, los políticos establecen una relación inmediata entre lo que busca la población y la creación del derecho penal, mientras acumulan réditos políticos.

13 Así, por ejemplo, el Senador Juan Carlos Vélez Uribe, dejando de lado el concepto del Consejo Superior de Política Criminal, señaló: "A mí me puede decir el consejo de política criminal mire, yo le recomiendo esto, y yo le puedo decir si me pareció, no me parece; yo interpreto es a mis electores y a los ciudadanos, a la gente de la calle, y la gente de la 


\section{En definitiva, el Congreso desconoció el carácter de última ratio del de-}

calle no está interpretando hoy lo que ese concepto dice; la gente de la calle está pensando otra cosa diferente, los medios de comunicación, la opinión pública, el país entero está pensando muy distinto a como está pensando hoy el consejo de política criminal.

Claro y podemos incluir esa recomendación renueva absolutamente ningún problema en que la incluyamos, pero esa no debe ser la decisión de esta comisión conjunta; nosotros no podemos salir mañana a decirle al país que la decisión que tomamos fue esa, porque no nos la van a perdonar, no la van a perdonar, el país está pidiendo sanciones eficaces para controlar a los conductores embriagados y allí están las víctimas, las víctimas de los conductores embriagados pidiendo y exigiendo decisiones fuertes, decisiones eficaces. Es que nosotros cada fin de semana vemos la cantidad de situaciones en las cuales se ven enfrascados conductores embriagados donde hay lesionados, donde hay muertos, o miren el caso de este muchacho Salamanca" (Congreso de la República de Colombia, Gaceta 19 de 2014).

A su vez, el representante a la Cámara, Orlando Velandia Sepúlveda, adujo que "uno ve el documento que ha hecho llegar a estas Comisiones Conjuntas el viceministro, sobre un pronunciamiento del Consejo Superior de Política Criminal, obviamente sin haber leído este documento ya varios compañeros lo habían manifestado sobre una inexistencia de política criminal en Colombia, sobre el uso inadecuado que se le esté dando al derecho penal como primera medida por la carencia de una política real de resocialización en las cárceles.

En fin, por todos esos buenos argumentos que se han traído, obviamente uno no los puede soslayar, ignorar o desconocer; lo que sí necesitamos, señores congresistas y estimados compañeros que escuchan a esta hora este debate, es que esta ciudadanía que está esperando a que este Congreso haga algo, que avancemos en el camino de ir solucionando un problema ya trágico en la sociedad colombiana.

Si miramos cómo ha evolucionado el proyecto, es todo y se ha reducido simplemente a que busquemos a través de unas circunstancias de agravación punitiva lo establecido en el artículo 109 del Código Penal sobre el homicidio culposo, claro que tendrá dificultades, claro que buscaremos medidas más integrales como las que bien explicaba el doctor Alfredo Deluque, pero es necesario que este Congreso dé una señal al pueblo colombiano de que sí estamos buscando una solución" (Congreso de la República de Colombia, Gaceta 19 de 2014).

Algunos congresistas expresaron su desacuerdo frente a posturas como las anteriores. Así, por ejemplo, el representante Alfredo Rafael Deluque sostuvo:

"Yo soy miembro del Consejo de Política Criminal, yo me opuse al proyecto de ley tal y como se aprobó en las Comisiones, han tenido unos avances, creo que hay que trabajar más en el tema de la prevención, lo que nosotros necesitamos es que no suban conductores ebrios, que haya conciencia colectiva aquí no se habla nada de la prevención tampoco se habla nada de fortalecer a las autoridades para que los controles sean aun superiores.

De manera tal que creo que es un proyecto cojo, aunque está tal y como lo dice, no en palabras mías sino el Consejo de Política Criminal haciendo alusión al concepto de populismo punitivo y al final del camino no vamos a lograr que en el país haya menos conductores ebrios haciendo daños a los habitantes de nuestro territorio. Así que dejo esa 
recho penal, y la necesidad de implementar otras medidas efectivas para la reducción significativa de la cantidad de víctimas de accidentes de tránsito por conducción en estado de embriaguez (Vargas y Castillo 2014, 79), pero logró dar "una señal” al pueblo colombiano, que tenía como propósito, obtener réditos políticos y electorales.

Con todo, entre 2015 y 2016, ha habido aproximadamente 517 muertes y lesiones atribuidas a los conductores en estado de embriaguez. Sin embargo, sólo se han presentado cuatro sentencias definitivas sobre esta conducta, entre 2013 y 2016, incluido Fabio Andrés Salamanca, quien aceptó cargos en 2014, por homicidio culposo (FGN 2017), y a quien no se le aplicaba la ley 1696 de 2013, por ser ésta posterior a los hechos.

Otro de los delitos, que se han puesto a prueba en el modelo anunciado corresponde a la penalización del aborto, que ha trascendido la reforma legislativa y ha llegado a discutirse en reformas constitucionales. Por tanto, se trata de un caso en el cual convergen el populismo punitivo y el populismo constitucional. Este último puede entenderse como una práctica política en la cual la Constitución es instrumentalizada para conseguir objetivos electorales y coyunturales específicos en el marco de agendas políticas individuales, con fundamento en hechos de gran connotación social, en los cuales el conglomerado centra su atención, permitiendo así una apropiación simbólica de la Constitución y la generación de capital político (Sarmiento 2013, 81).

Aunque los intentos por volver a criminalizar los casos de aborto despenalizados por la Corte Constitucional, no han sido exitosos, en las tentativas de reforma constitucional se puede evidenciar el populismo penal. En este caso, la razón de ser del debate constitucional recae en una decisión de la Corte Constitucional - la Sentencia C-355 de 2006-, que despenalizó el aborto en tres supuestos de hecho. Sin embargo, después de este avance de la jurisprudencia, se presentó un proyecto de Acto Legislativo (06 de 2011), para reformar el artículo 11 de la Constitución de modo que se protegiese el derecho a la vida, desde el momento de la fecundación. Este proyecto fue archivado en debate el 12 de octubre de 2011 (Congreso de la República de Colombia, Gaceta 5 de 2012). Tras ese intento fallido, "Unidos por la Vida", una plataforma ciudadana, inició el proceso de recolección de firmas y movilización social para convo-

constancia señor Presidente, debido a que considero que no hemos resuelto el tema de fondo" (Congreso de la República, Gaceta 75 de 2014).

Esta obra está bajo una Licencia Creative Commons

Atribución-NoComercial-SinDerivar 4.0 Internacional, IIJ-UNAM.

Boletín Mexicano de Derecho Comparado, núm. 155, mayo-agosto de 2019, pp. 1047-1079. 
car un referendo en contra del aborto. Sin embargo, una vez presentadas las firmas, la Registraduría decidió anular casi un millón de éstas y la posibilidad del referendo se derrumbó.

Aunado a la movilización, las propuestas de reforma dejaron de lado los múltiples estudios que han señalado que no es posible cambiar la cifra de abortos realizados mediante modificaciones al régimen penal; el aborto, aún penalizado, constituye una conducta frecuente, cobijada por la ineficacia instrumental del Estado (Sarmiento 2013, 104). A su vez, los proyectos de acto legislativo mencionados buscaban ocasionar una regresión respecto a lo establecido en la jurisprudencia de la Corte Constitucional.

El debate en torno al proyecto de Acto Legislativo, el cual intentó prohibir el aborto, permitió constatar un abuso discursivo, que acudía a afirmaciones éticas o morales difíciles de eludir y de debatir racionalmente. Como señala García (2014, 262), para los conservadores lo importante es que exista la prohibición al aborto, sin tener en cuenta si la población continúa abortando con mayor o igual frecuencia, y en condiciones aún peores a raíz de la prohibición impuesta. Así, "vencer en el papel, obtener una victoria simbólica, un triunfo moral, es algo que muchas veces preferimos a vencer en los hechos y quedar derrotados en el papel... Haber ganado la batalla de las palabras es lo que cuenta para ellos".

En el caso del referendo se observa cómo la ciudadanía, actuando guiada en gran parte por motivos religiosos, intenta incidir de manera directa en la política criminal de un Estado laico, para penalizar totalmente el aborto. Se trataría de la traducción inmediata de los intereses de un sector de la sociedad en la criminalización de una conducta en la cual se encuentran en juego el ejercicio de distintos derechos, que han sido reconocidos por la Corte Constitucional.

Vale la pena señalar que, posteriormente, surgieron iniciativas opuestas, con tendencia hacia la despenalización del aborto. Por un lado, se presentó el proyecto de Acto Legislativo 16 de 2012 Cámara, que pretendía adicionar a la Constitución una disposición que permitiese la interrupción del embarazo en los casos señalados por la ley. Sin embargo, fue archivado sin generar un debate serio sobre la materia (Congreso de la República de Colombia, Gaceta 912 de 2012). Por otro lado, se presentó un proyecto de ley que pretendía avanzar en la materia, proyecto 209 de 2016 Cámara, mediante la despenalización del aborto durante las primeras 24 semanas de gestación, que fue archivado por tránsito de legislatura el 21 de junio de 2016. 
Esta revista forma parte del acervo de la Biblioteca Jurídica Virtual del Instituto de Investigaciones Jurídicas de la UNAM

La ineficacia de la norma, en todo caso, resulta más que notable. En el país se realizan entre 43,000 y 130,000 abortos al año, ${ }^{14}$ mientras que sólo ha habido 129 condenas sobre la mujer que se ha practicado el aborto (FGN 2017 y El Espectador 2012).

A continuación, se expondrán los resultados de la aplicación del modelo propuesto a las conductas antes descritas, para, con posterioridad, expresarlas gráficamente.

\section{TABLA 7}

\section{OPERACIONALIZACIÓN DE LOS FACTORES}

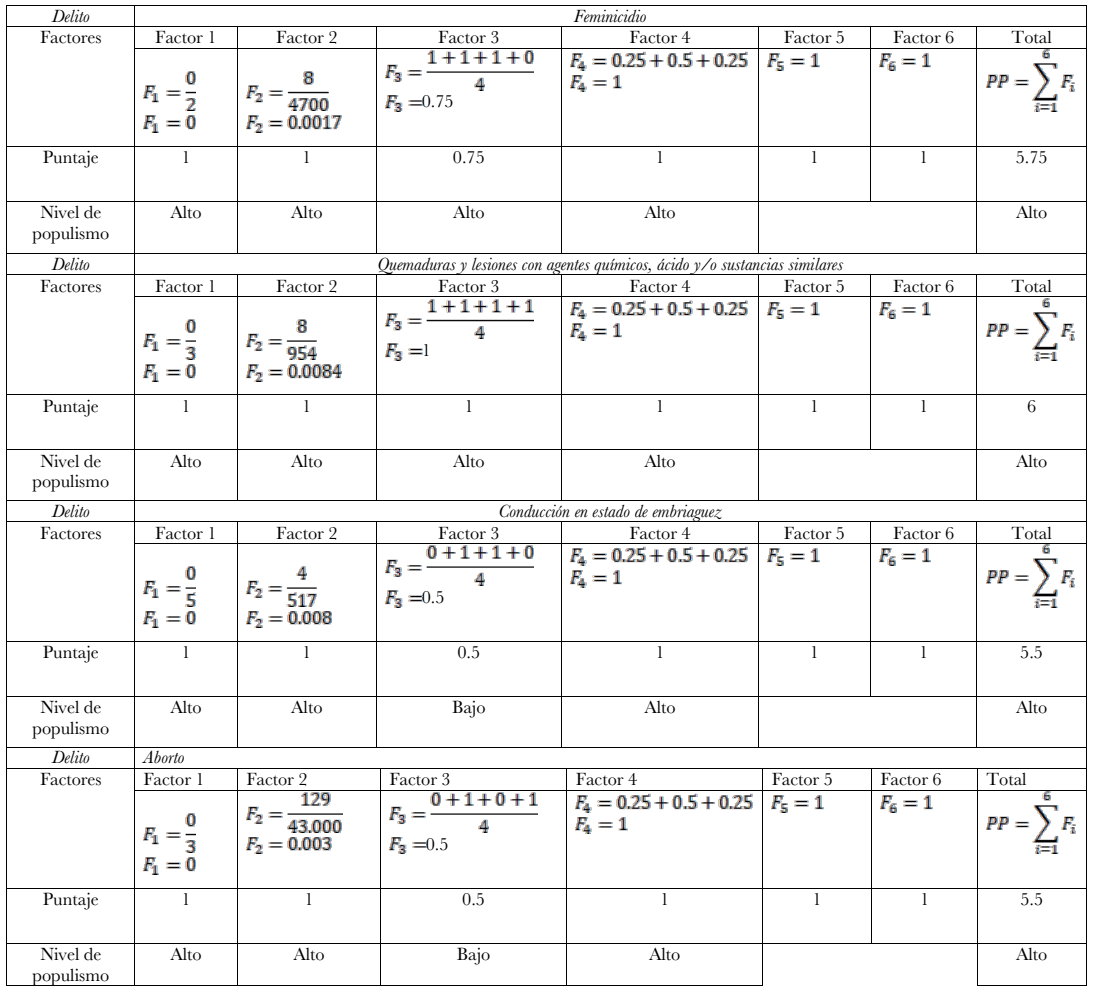

FUENTE: elaborado por los autores.

14 Las cifras sobre abortos en Colombia son inciertas y existen múltiples inconsistencias sobre el número de abortos clandestinos realizados en el país, por su misma naturaleza oculta. Véase Rubio (2015).

Esta obra está bajo una Licencia Creative Commons

Atribución-NoComercial-SinDerivar 4.0 Internacional, IIJ-UNAM.

Boletín Mexicano de Derecho Comparado, núm. 155, mayo-agosto de 2019, pp. 1047-1079. 
Los anteriores resultados se ilustran en la siguiente figura:

\section{ILUSTRACIÓN 1}
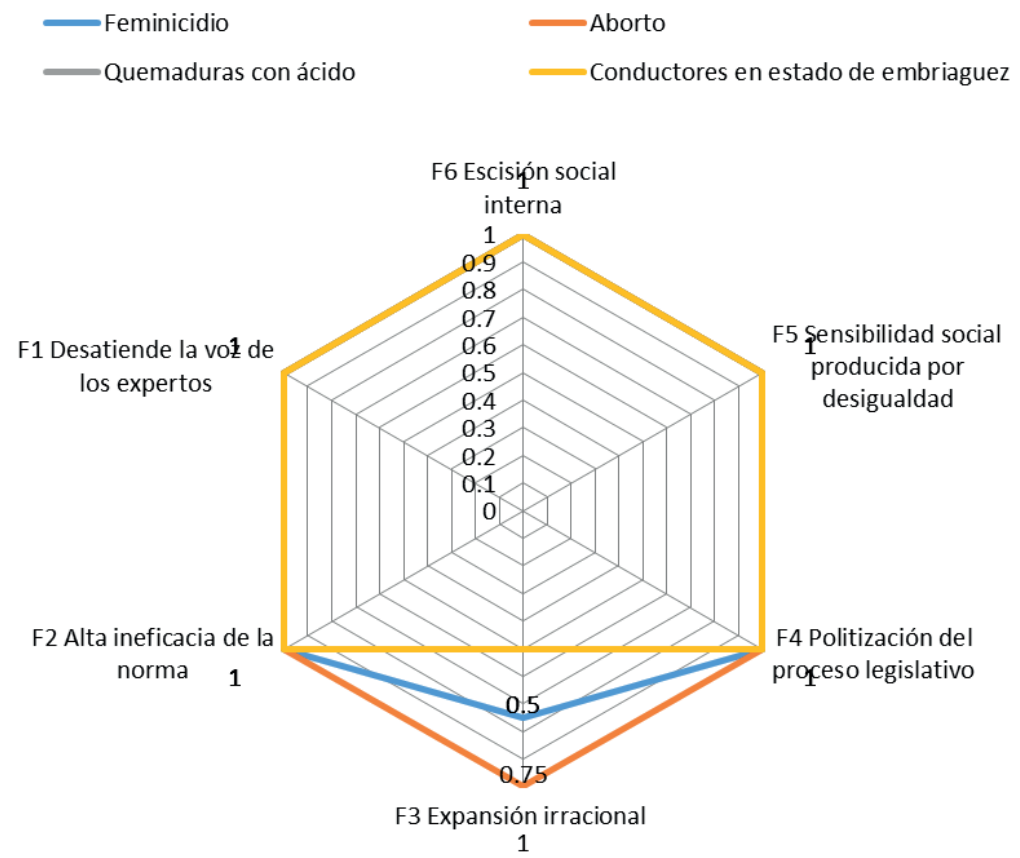

FUENTE: elaborado por los autores.

\section{Conclusiones}

Durante los estados de excepción en Colombia, constantemente declarados desde la segunda mitad del siglo XX, el derecho penal autoritario construyó una justicia penal de excepción que fue ejemplo claro de populismo punitivo y derecho penal del enemigo en el país. En tiempos de legislación ordinaria, el legislador colombiano ha mostrado una tendencia a la hora de responder ante hechos coyunturales, presión mediática y demandas sociales en materia de prevención de delitos, como sucedió en los casos del feminicidio, las quemaduras con ácido, la conducción en estado de embriaguez y el aborto. 
En estos casos, el populismo punitivo permitió a gobernantes y legisladores colombianos aprovechar los efectos simbólicos del derecho penal para apaciguar a las masas, a la opinión pública y a las víctimas de distintas conductas, que reaccionaban ante la ineficacia estatal para evitar los delitos. Los actores estatales utilizaron el derecho penal para enviar una señal de que estaban haciendo algo para solucionar las distintas problemáticas que agobiaban al país y prevenir delitos, implementando medidas penales represivas cuya eficacia no era comprobada, puesto que ni siquiera eran tenidos en cuenta los conceptos de los expertos, y, a su vez, dejaron de lado las verdaderas causas de la realización de ciertas conductas y las medidas que realmente podían conducir a resultados positivos en materia de prevención. De ese modo, se ahorraron la implementación de políticas públicas destinadas a mejorar las condiciones sociales, económicas y culturales, mientras la ciudadanía temerosa se preocupaba más por la seguridad que por la precariedad de sus condiciones de vida, dejando que la desigualdad creciera.

Estas conclusiones estuvieron acompañadas de un modelo que, como propuesta, presenta indicadores que ofrecen algún medio para evaluar reformas legales en Colombia, que puedan ser acusadas de populistas. La frontera, en algunas ocasiones, no parece clara, y por ello, este modelo plantea que, más allá de los argumentos que presente una comisión de expertos sobre la materia, exista una evidencia empírica que dé cuenta de un umbral de populismo.

\section{REFERENCIAS BIBLIOGRÁFICAS}

Barata, Alessandro. 2004. "Seguridad". En Criminología y Sistema Penal, dir. Carlos Elbert y coord. Laura Belloqui. Buenos Aires: Euros Editores S.R.L.

Bassombrío, Carlos y Dammert, Lucía. 2013. Seguridad y populismo en América Latina: lecciones, constataciones novedosas y temas emergentes. Washington: Woodrow Wilson Center Update on the Americas.

Cavadino, Michael y Dignan, James. 2006. "Penal policy and political economy". Criminology and Criminal fustica 6 (4): 435-456.

Chevigny, Paul. 2003. "The populism of fear: politics of crime in the Americas". Punishment and Society 5(1): 77-96. 
Comisión Asesora de Política Criminal. 2012. Diagnóstico y propuesta de lineamientos de politica criminal para el Estado colombiano. https://wrere.minjusticia.gov.co/Portals/0/INFO\%20POLI\%20CRIMINAL_FINAL23NOV.pdf.

DíAz, Carlos. 2014. "Lesiones personales causadas con ácidos, álcalis, sustancias similares o corrosivas, una reforma del 2013". Revista de Derecho Público 33 (julio-diciembre).

DíEz, José. 2004. "El nuevo modelo penal de la seguridad ciudadana", Revista Electrónica de Ciencia Penal y Criminología 6 (03): 1-34

DurÁn, Diana. 2012. "Promoverán la ley Rosa Elvira", El Espectador, 10 de julio, http://wrere.elespectador.com/noticias/judicial/promoveran-ley-rosaelvira-articulo-358764.

El Tiempo. 2014. "En video: diez momentos clave de la vida del caso Natalia Ponce de León", 5 de septiembre, http://wwreeltiempo.com/bogota/ momentos-clave-del-caso-natalia-ponce-de-leon/14421718.

EL Tiempo. 2015. "Han sido años de dolor y de fortaleza: hermana de Rosa Elvira Cely", 3 de junio, http://wrere.eltiempo.com/politica/congreso/ penalizacion-del-feminicidio/15884275.

FERrajoli, Luigi. 2013. "El populismo penal en la sociedad del miedo". En La emergencia del mied, ZAFFARONI, Eugenio; Ferrajoli, Luigi; TORRES, Sergio y BASílico, Ricardo. Buenos Aires: Ediar.

García, Mauricio. 2014. La eficacia simbólica del derecho: Sociología politica del campo jurídico en América Latina, 2a. ed. Bogotá: IEPRI.

GARLAND, David. 2005. La cultura del control: Crimen y orden social en la sociedad contemporánea. Barcelona: Gedisa.

González, Julio. 2015. "Reformar o abolir el sistema Penal ¿Cómo?”. ¿Reformar o abolir el sistema penal?, ed. D. Arias. Bogotá: Siglo del Hombre Editores.

ItUrRalde, Manuel. 2010. Castigo, liberalismo autoritario y justicia penal de excepción. Bogotá: Siglo del Hombre Editores.

ITURRALDE, Manuel. 2007a. "La sociología del castigo de David Garland: El control del crimen en las sociedades modernas tardías". Crimen y castigo en la modernidad tardía, David Garland. Bogotá: Siglo del Hombre Editores.

ITURRALDE, Manuel. 2007b. "Order first, justice later: Emergency criminal policy as a path towards development. The Colombian Case. Sortuz. Oñati". Journal of Emergent Socio-legal Studies 1 (2): 55-76. 
ITURRALDE, Manuel. 2003, "Guerra y derecho en Colombia: el decisionismo político y los estados de excepción como respuesta a la crisis de la democracia", Revista Estudios Sociales 15: 29-46.

Kleiman, Mark. 2015. Cuando la fuerza bruta fracasa. Cómo lograr que haya menos crimen y menos castigo. Bogotá: Editorial Universidad de los Andes.

LARraUri, Elena. 2006. "Populismo punitivo... y cómo resistirlo", Jueces para la democracia 55, https://wrere.academia.edu/9812655/Populism-o_Punitivo.

LOdoÑo, Hernando y Restrepo, Adrián. 2011. "Guerra contra las drogas, populismo punitivo y criminalización de la dosis personal". Estudios Políticos 39: 141-167.

Martínez, Mauricio. 2008. "Populismo punitivo, mayoría y víctimas". Nomos, 2: 183-199.

MuÑoz, Julián. 2009. "Populismo punitivo y una «verdad» construida". Revista Nuevo Foro Penal 72: 13-42.

Restrepo, Diana. 2015. “¿Puede ser la mediación una vía de escape?”. ¿Reformar o abolir el sistema penal?, ed. D. Arias. Bogotá: Siglo del Hombre Editores.

SEMANA. 2013. "El joven borracho que conducía por Bogotá a 160 kph", 14 de julio http://wrere.semana.com/nacion/articulo/el-joven-borracho-conducia-bogota-160-kph/350869-3.

Rubio, Mauricio. 2015. "El mito de los 400 mil abortos en Colombia". Revista de Economía Institucional 17 (33): 253-274.

SARmiento, Juan. 2013. "El populismo constitucional en Colombia, hacia la instrumentalización simbólica de la Constitución por medio de proyectos de actos legislativos fallidos". Estudios Socio-furídicos 15 (2): 75 109.

Sotomayor, Juan. 2007. "Las recientes reformas penales en Colombia: un ejemplo de irracionalidad legislativa". Revista Nuevo Foro Penal 71: $13-66$.

URIBE, Juan. 2012. “¿Puede hablarse de populismo punitivo en Colombia?", Revista Nuevo Foro Penal 8 (78).

URREgo, Rodrigo. 2013. "El tema del aborto se moverá en un referendo" Semana, 4 de febrero, http://wrerr.semana.com/nacion/articulo/el-tema-delaborto-movera-referendo/332000-3. 
VARGas, Renato y Castillo, Laura. 2014. "La sanción penal de los conductores ebrios en Colombia: entre las dificultades dogmáticas y la ausencia de una política criminal coherente". Civilizar 14 (26): 67-86.

VÉLEZ, Luis. 2007. “¿Se encuentra justificada la actual política criminal contra agresores sexuales?”. Nuevo Foro Penal 71: 92-114.

WACQUant, Loïc. 2004. Las cárceles de la miseria. Buenos Aires: Manantial.

Wilkinson, Richard y Pickett, Kate. 2009. Desigualdad. Un análisis de la (in)felicidad colectiva. Madrid: Tuner Publications.

ZAFFARONI, Eugenio R. 2011. El enemigo en el derecho penal, $2^{a}$ edición. México: Coyoacán. 